\title{
KEBERDAYAAN MASYARAKAT SEKITAR HUTAN DAN KEBERHASILAN PENGELOLAAN TAMAN HUTAN RAYA WAN ABDUL RACHMAN DI PROVINSI LAMPUNG
}

\section{Community Empowerment Around The Forest and Successful Management of Taman Hutan Raya Wan Abdul Rachman in Lampung Province}

\author{
Isti Putri Utami ${ }^{1 *}$, Tubagus Hasanuddin ${ }^{2}$, Abdul Mutolib ${ }^{2}$ \\ ${ }^{1}$ Universita s Lampung, Jl. Prof. Soemantri Briodjonegoro No. 1 Bandar Lampung 35145 \\ ${ }^{2}$ Universita s Lampung, Jl. Prof. Soemantri Briodjonegoro No. 1 Bandar Lampung 35145 \\ *email koresponden: istiputri1995@gmail.com dan a mutolib24@yahoo.com
}

\begin{abstract}
Abstrak
Tujuan penelitia n ini untuk mengetahuitingkat keberdayaan masyarakat dan keberhasilan pengelolaan Ta hura WAR serta ka itan antara keduanya. Responden yang digunakan adalah 30 orang yang termasuk dalam anggota Kelompok Pengelo la dan Pelestari Hutan di Kelurahan Sumber Agung yang ditentukan secara purposive. Pengumpulan data dengan wa wa ncara dan Focus Group Disscussion. Metode a nalisis yang digunakan adalah analisis deskriptif, se dangkan u nt uk analisis data digunakan uji Rank Spearman. Berdasarkan hasil temuan, diketahuijika tingkat keberdaya an ma syarakat sekitarTa hura WAR secara keseluruhan masuk dalam klasifikasi sedang. Hal tersebut berdasarkan tin gk at pe ndidik an yang rendah sehingga kurangnya keterampilan masyarakat KPPH Ta hura WAR dalam mengelola Tahura WAR. Keberhasila n pengelolaan Tahura WAR termasuk dalam kategori berhasil secara keseluruhan. Hal tersebut berda sarkan pa da keberhasila n pengelolaan Tahura WAR dalam menjalankanfungsinya sehing ga berdampak pada peningkatan pendapatan serta perkembangan usaha pertanian masyarakat KPPH Tahura WAR. Keb erda ya an ma syarakat sekitar Tahura WAR memiliki hubungan ny ata yang kuat dengan keberhasilan pengelolaan Tahura WAR di Provinsi La mpung. Berdasarkan Hal tersebut, diharapkan Dina s Kehutanan dan UPTD Tahura WAR d apat meningkatkan keberdayaan ma syarakat melalui program pemberdayaan sehingga Tahura WAR dapat dimanfaatkan dengan lebih optimal.
\end{abstract}

Kata kunci: Keberdayaan, keberhasila n pengelolaan, tahura WAR

\begin{abstract}
The purpose of this research is to determine the level of community empowerment around Tahura WAR, the success of Tahura WAR management, and the relationship between them. The respondents were 30 people whom members of Forest Management and Conservation Group in Sumber Agung Village who were determined purposively. Data were collected through interviews and Focus Group Disscussion. The analyticalmethod is descriptive analysis, while data analysis used the Spearman Rank test. Based on the findings, it is known: the level of communityempowermentaround Tahura WAR is included in the medium classification based on the lowlevel of education so that the lack of skills of the FMCG Ta hu ra WAR community in managing Tahura WAR. The successfulmanagement of Ta hura WAR is included in the overall success categorybased on the success of the management of Tahura WAR in carrying out its functions so that it has an impact on increasing income and the development of agricultural businesses. Community empowerment around Ta hura WAR has a strong relationship with the successfulmanagement of Tahura WAR. Based on this, it is hoped that Fore stry Service and UPTD Tahura WAR can increase community empowerment through empowerment programs so that Tahura WAR can be utilized more optimally.
\end{abstract}

Keywords: Empowerment, management success, tahura WAR 


\section{PENDAHULUAN}

Hutan merupakan sebuah kawasan dimana didalamnya terdapat berbagai jenis makhluk hidup seperti tumbuhan maupun tanaman, hewan, serangga, serta mikro-organisme dalam tanah yang menjadi sumber oksigen dunia. Hutan memiliki fungsi penting bagi kehidupan manusia karena selain sebagai penyedia oksigen hutan juga berfungsi dalam mengatur tata air, penanggulangan bencana, serta sebagai tempat pelestarian maupun perlindungan berbagai flora dan fauna. Hutan sangatlah penting bagi suatu negara karena mampu mencegah terjadinya bencana alam terutama banjir maupun tanah longsor melalui pengaturan tata air oleh tumbuhan ataupun tanaman, sebagai sumber devisa negara melalui kegiatan ekspor hasil hutan baik kay u maupun non kayu, serta hasil hutan juga dapat dimanfaatkan untuk kesejahteraan masyarakat. Menurut (Departemen Kehutanan, 2014) Indonesia memiliki lebih dari 50 juta penduduk miskin yang tinggal di sekitar atau di dalam hutan dan menggunakan hasil hutan untuk memenuhi kebutuhan hidupnya. Oleh karena itu pemanfaatan hutan sangatlah penting untuk meningkatkan kesejahteraan masyarakat pemanfaat hutan (Winarwan, 2011).

Berdasarkan Peraturan Pemerintah RI No. 34 tahun 2002 yang membahas tentang Pengelolaan Hutan, diketahui bahwa hutan dibagi menjadi 3 jenis dengan pertimbangan tertentu menjadi hutan konservasi dan kawasan pelestarian alam, hutan lindung, serta hutan produksi. Hutan konservasi merupakan kawasan yang dijadikan tempat pengawetan atau pelestarian beraneka macam flora, fauna serta ekosistemnya. Menurut (Alviya, 2006) hutan konservasi dan kawasan pelestarian alam memiliki pengaruh besar pada lingkungan dan ekonomi masyarakat sekitarny a (Alviya, 2006). Hutan lindung merupakan kawasan yang ditetapkan untuk dilindungi dalam rangka menjaga fungsi ekologisnya sehingga dapat terus dimanfaatkan oleh masyarakat sekitar. Hutan produksi merupakan kawasan yang dikelola untuk memproduksi berbagai macam hasil hutan.

Taman Hutan Raya atau Tahura termasuk ke dalam jenis hutan konservasi dimana menjadi tempat pelestarian alam dengan tujuan agar dapat melestarikan koleksi flora dan fauna yang dapat digunakan untuk kepentingan umum. Tugas pokok Tahura adalah untuk melindungi sistem penyangga kehidupan; pengawetan keaneka-ragaman flora dan fauna; konservasi, koleksi, edukasi, dan riset; tempat wisata; dan meningkatkan sosial ekonomi masyarakat sekitar. Tahura memiliki fungsi diberbagai bidang yaitu lingkungan, sosial, ekonomi, dan pendidikan. Dibidang lingkungan Tahura berfungsi sebagai tempat pelestarian maupun pengawetan berbagai flora dan fauna. Dibidang sosial, tahura berfungsi sebagai sumber mata pencaharian masyarakat sekitar hutan. Dibidang ekonomi, tahura berfungsi sebagai sumber ekonomi melalui pemanfaatan hasil hutan baik kayu atau non kayu, serta sebagai tempat wisata. Dibidang pendidikan, tahura berfungsi sebagai tempat penelitian atau riset.

Tahura Wan Abdul Rachman (WAR) adalah taman hutan raya di Provinsi Lampung yang memiliki luas sebesar 22.245,50 ha dan dikelilingi oleh wilayah administratif Kota Bandar Lampung dan Kabupaten Pesawaran (UPTD Tahura WAR, 2017). Awalnya Tahura WAR adalah kawasan hutan lindung dengan sebutan Gunung Betung Register 19, namun karena kawasan tersebut mengalami kerusakan parah yang dilakukan oleh penduduk sekitar oleh karena itu dirubah menjadi kawasan hutan konservasi bernama Tahura WAR untuk meminimalisir kerusakan hutan yang dapat terjadi. Perubahan tersebut tertuang dalam Surat Keputusan Menteri Kehutanan No. 408/KPTS-II/1993. Sejak tahun 2012, pengelolaan Tahura WAR Provinsi Lampung mengikut sertakan masyarakat sekitar melalui sistem pengelolaan kolaboratif yang termuat pada Peraturan Daerah Provinsi Lampung No. 3 tahun 2012 (Nurlia, Martin, \& Winarno, 2015). 
Kegiatan pemberdayaan yang dilakukan oleh Dinas Kehutanan dan UPTD Tahura WAR diharapkan mampu merubah perilaku (pengetahuan, sikap, dan keterampilan) masyarakat sekitar hutan. Perubahan perilaku tersebut bertujuan agar masyarakat dapat lebih baik dalam mengelola Tahura WAR sehingga mampu mengelola hutan tersebut dan berdampak pada peningkatan kesejahteraan hidupnya (Sugiatono \& Dharmayanthi, 2016). Hal tersebut sesuai dengan penelitian (Anggraini, Rangga, \& Hasanuddin, 2019), bahwa peningkatan pengetahuan akan berdampak pada peningkatan kesejahteraan seseorang. Keberdayaan masyarakat merupakan masyarakat yang telah berdaya dan mampu memanfaatkan semua potensi baik didalam dirinya maupun disekitarnya dengan baik sehingga ia mampu mencapai kesejahteraan hidupnya. (Hasanuddin \& Muhammad, 2012), menyatakan bahwa keberdayaan seseorang dapat ditingkatkan dalam hal kemampuan untuk mengakses sumber ekonomi, pengembangan usaha, serta kerjasama antar individu dalam melakukan usaha bersama. Berdasarkan uraian di atas, rumusan masalah penelitian ini adalah bagaimana tingkat keberdayaan masyarakat sekitar Tahura WAR, bagaimana keberhasilan pengelolaan Tahura WAR, serta bagaimana hubungan antara keberdayaan masyarakat sehitar dengan keberhasilan pengelolaan Tahura WAR. Oleh karena itu penelitian ini bertujuan untuk mengetahui tingkat keberdayaan masyarakat di sekitar Tahura WAR dan keberhasilan pengelolaan Tahura WAR serta kaitan antara keduanya.

\section{METODE PENELITIAN}

Penelitian dilakukan pada Agustus 2019 di Kelurahan Sumber Agung, Kota Bandar Lampung. Lokasi penelitian ditentukan secara purposive atas pertimbangan bahwa masyarakat di kelurahan tersebut merupakan salah satu masyarakat yang berada disekitar Tahura WAR dan memanfaatkan Tahura WAR untuk pemenuhan kebutuhannya. Metode penentuan sampel ditentukan secara purposive. Responden penelitian adalah 30 orang yang termasuk ke dalam KPPH di Kelurahan Sumber DOI:10.25077/joseta.v2i2.237
Agung. Data dikumpulkan melalui wawancara dan Focus Group Disscussion (FGD). Metode analisis yang digunakan analisis deskriptif, sedangkan analisis data adalah uji Rank Spearman.

\section{HASIL DAN PEMBAHASAN}

\section{Keadaan Umum Daerah Penelitian}

Tahura WAR Provinsi Lampung memiliki luas $22.245,50$ ha yang dikelilingi oleh wilayah administratif Kota Bandar Lampung dan Kabupaten Pesawaran. Tahura WAR dikelilingi oleh 7 Kecamatan yaitu Kecamatan Gedong Tataan, Kedondong, Padang Cermin, Way Lima, Teluk Betung Barat, Teluk Betung dan Kemiling (UPTD Tahura WAR, 2006). Pengelolaan Tahura WAR dilakukan secara kolaborasi dengan mengikut sertakan masyarakat sekitar Tahura WAR.

Pada pengelolaan Tahura WAR, terdapat 4 stakeholder yang memiliki peran dan kepentingan yang berbeda yaitu Dinas Kehutanan dan UPTD Tahura WAR, Lembaga Penelitian dan Pendidikan, Lembaga Swadaya Masyarakat dan KPPH Tahura WAR. Dinas Kehutanan dan UPTD Tahura WAR memiliki kepentingan untuk bertanggung jawab dalam pengelolaan Tahura WAR, kelestarian hutan, dan kesejahteraan masyarakat; serta berperan untuk mengadakan program dan pelaksanaan pengelolaan Tahura WAR, penempatan dan peningkatan SDM pengelola Tahura WAR, serta melakukan pemberdayaan masyarakat. Lembaga Penelitan dan Pendidikan memiliki kepentingan untuk melakukan penelitian dan pendidikan yang berkaitan dengan Tahura WAR, serta memiliki peran untuk menyediakan, serta memberikan masukan tentag data-data yang dibutuhkan dalam pelaksanaan pengelolaan hutan Tahura WAR. Lembaga Swadaya Masyarakat memiliki kepentingan untuk kelestarian kawasan dan pemberdayaan masyarakat; sedangkan perannya adalah untuk penguatan kelembagaan serta pemberdayaan masyarakat. Masyarakat yang termasuk kedalam KPPH Tahura WAR memiliki kepentingan untuk bertanggung jawab dalam 
pengelolaan lahan Tahura WAR yang dikelolanya, serta sebagai sumber mata pencaharian; serta peran masyarakat adalah untuk menjaga kawasan Tahura WAR tetap lestari. fauna, tempat pencegahan bencana alam, dan sebagai tempat untuk pemenuhan kebutuhan sehari-hari melalui pemanfaatan hasil hutan), dibagi menjadi keberdayaan dalam hal pengetahuan, sikap, dan

Tabel 1. Tingkat Keberdayaan Masyarakat Sekitar Tahura WAR di Provinsi Lampung

\begin{tabular}{llll}
\hline Interval (Skor) & Klasifikasi & Jumlah $($ Orang) & Persentase (\%) \\
\hline $37-39.67$ & Rendah & 5 & 16.67 \\
$39.68-42.35$ & Sedang & 15 & 50.00 \\
$42.36-45.03$ & Tinggi & 10 & 33.33 \\
\hline Jumlah & & 30 & 100.00 \\
\hline Sum & & &
\end{tabular}

Sumber: data yang diolah, 2019

Sebagai usaha pencapaian tujuan pengelolaan Tahura WAR untuk mem-berdayakan masyarakat, digunakan pola tanam campuran dengan sistem Agroforestri. Agroforestri merupakan cara pengelolaan lahan dengan menggabungkan pohon dan tanaman non kayu untuk tujuan peningkatan keuntungan. (Haryanto, 2011). Adapun tanaman yang dikelola oleh masyarakat yang tergabung dalam KPPH Tahura WAR yaitu tanaman tajuk tinggi (karet, durian, petai, tangkil, kelapa, aren, kayu manis, cempaka) tajuk tengah (kopi dan coklat) dan tajuk rendah (pisang, vanili, dan lada).

\section{Karakteristik Responden}

Berdasarkan data yang telah diperoleh melalui penyebaran kuesioner dalam penelitian ini, diperoleh karakteristik responden yaitu usia responden berada pada rentang antara 44-58 tahun dengan rata-rata umur 50 tahun. Tingkat pendidikan formal yang telah dicapai responden adalah SD $(33,3 \%)$, SMP $(46,7 \%)$, SMA $(13,3 \%)$, dan D-III $(6,67 \%)$. Jenis usaha yang dilakukan oleh responden tidak terbatas pada petani pengelolaan dan pelestarian hutan saja, tetapi juga berdagang, maupun melakukan industri rumah tangga (pembuatan kopi bubuk).

\section{Tingkat Keberdayaan Masyarakat Sekitar Tahura WAR}

Tingkat keberdayaan masyarakat pada pengelolaan Tahura WAR (sebagai objek wisata, tempat penelitian, tempat konservasi beragam flora dan keterampilan. Berikut tingkat keberdayaan masyarakat sekitar Tahura WAR di Provinsi Lampung.

Tabel 1 menunjukkan bahwa, sebanyak 10 responden $(33,33 \%)$ termasuk dalam klasifikasi tingkat keberdayaan yang tinggi, 15 responden (50\%) termasuk dalam klasifikasi tingkat keberdayaan sedang, dan 5 responden $(16,67 \%)$ termasuk dalam klasifikasi tingkat keberdayaan rendah. Hal tersebut disebabkan karena keterampilan masyarakat yang masih rendah sehingga mereka kurang terlibat dalam membantu kegiatan penelitian di Tahura WAR. Tingkat keberdayaan masyarakat sekitar Tahura WAR di Provinsi lampung, secara rinci disajikan pada Tabel 2.

Tabel 2. Tingkat Keberdayaan Masyarakat Sekitar Tahura WAR di Provinsi Lampung berdasarkan Indikator

\begin{tabular}{clll}
\hline No. & Keberdayaan & $\begin{array}{l}\text { Rerata } \\
\text { Skor }\end{array}$ & Klasifikasi \\
\hline 1. & Pengetahuan & 14.53 & Tinggi \\
2. & Sikap & 14.93 & Tinggi \\
3. & Keterampilan & 12.03 & Sedang \\
\hline
\end{tabular}

Sumber: data y ang diolah, 2019

Tingkat keberdayaan masyarakat sekitar Tahura WAR dalam hal pengetahuan termasuk dalam klasifikasi tinggi. Hal ini disebabkan karena masyarakat Tahura WAR telah mengetahui dengan baik fungsi-fungsi maupun pengelolaan Tahura WAR. Menurut penelitian (Setyaningsih, Gayatri, \& 
Eddy, 2017), kesempatan memperoleh informasi maupun keanggotaan dalam organisasi dapat mempengaruhi tinggi rendahnya pengetahuan seseorang. Oleh karena itu, Dinas Kehutanan Provinsi Lampung melalui UPTD Tahura WAR sering melakukan kegiatan penyuluhan kepada KPPH Tahura WAR dalam pengelolaan Tahura WAR sehingga masyarakat tidak mengalami kesulitan dalam mengakses informasi yang berkaitan dengan pengelolaan Tahura WAR.

Tingkat keberdayaan masyarakat sekitar Tahura WAR dalam hal sikap termasuk dalam klasifikasi tinggi yang artinya masyarakat KPPH Tahura WAR terbuka untuk setiap inovasi, program, maupun anjuran dari Dinas Kehutanan Provinsi Lampung. Hal tersebut dapat terlihat dari masyarakat yang menyetujui beragam inovasi, program yang diberikan dan ikut mendukung pengelolaan Tahura WAR. UPTD Tahura WAR juga memiliki tujuan agar masyarakat Tahura WAR dapat memiliki akses legal dalam pemanfaatan lahan Tahura WAR sehingga masyarakat dapat memanfaatkan Tahura WAR untuk me-ningkatkan kesejahteraannya.

Tingkat keberdayaan masyarakat sekitar Tahura WAR dalam hal keterampilan termasuk dalam kategori sedang. Hal tersebut dikarenakan keterampilan masyarakat yang masih kurang maksimal dalam memanfaatkan dan mengelola Tahura WAR. Berdasarkan data yang didapatkan, dengan presentase SD (82\%), SMP (10\%), dan SMA (4\%) (Tim SHK Lestari, 2008). Hal tersebut juga ikut menyebabkan keterampilan masyarakat KPPH Tahura WAR masuk dalam klasifikasi sedang. Senada dengan penelitian (Suwarno, Sartohadi, Sunarto, \& Sudharta, 2014), pendidikan sangat mempengaruhi keterampilan, perilaku, serta sikap masyarakat. Masyarakat juga jarang ikut serta dalam upaya konservasi Tahura WAR karena mayoritas tanaman yang mereka tanam adalah tanaman tajuk tinggi yang tidak memerlukan upaya pengelolaan yang intensif.

\section{Tingkat Keberhasilan Pengelolaan Tahura WAR}

Keberhasilan pengelolaan Tahura WAR dilihat berdasarkan beberapa indikator yaitu output atau keluaran (terlaksanakannya fungsi-fungsi Tahura WAR sebagai objek wisata, tempat penelitian, tempat konservasi beragam flora dan fauna, tempat pencegahan bencana alam, dan sebagai tempat untuk pemenuhan kebutuhan sehari-hari melalui pemanfaatan hasil hutan), outcome atau hasil (peningkatan pendapatan masyarakat anggota KPPH Tahura WAR, peningkatan kemampuan KPPH), benefit atau manfaat (perkembangan usaha pertanian). Berdasarkan ketiga indikator tersebut, tingkat keberhasilan pengelolaan Tahura WAR termasuk dalam klasifikasi berhasil. Berikut tingkat keberhasilan pengelolaan Tahura WAR secara rinci.

Tabel 3. Tingkat Keberhasilan Pengelolaan Tahura WAR di Provinsi Lampung

\begin{tabular}{llll}
\hline Interval (skor) & Klasifikasi & Jumlah (Orang) & Persentase (\%) \\
\hline $32-35.33$ & Tidak berhasil & 0 & 0.00 \\
$35.34-38.67$ & Kurang berhasil & 10 & 33.33 \\
$38.68-42.01$ & Berhasil & 20 & 66.67 \\
\hline Jumlah & & 30 & 100.00 \\
\hline
\end{tabular}

Sumber: data yang diolah, 2019

masyarakat sekitar kurang memiliki kemampuan dalam membantu kegiatan penelitian yang ada di Tahura WAR. Hanya ketua KPPH saja yang ikut membantu kegiatan penelitian yang ada di Tahura WAR. Selain itu, tingkat pendidikan masyarakat sekitar Tahura WAR termasuk dalam kategori rendah
Tabel 3 menyatakan bahwa sebanyak 0 responden (0\%) menyatakan bahwa pengelolaan Tahura WAR masuk dalam klasifikasi tidak berhasil. Sebanyak 10 responden $(33,33 \%)$ menyatakan bahwa pengelolaan Tahura WAR masuk dalam klasifikasi kurang berhasil. Sebanyak 20 responden (66.67\%) 
menyatakan pengelolaan Tahura WAR masuk dalam klasifikasi berhasil. Hal ini disebabkan karena telah terlaksananya fungsi dan pengelolaan Tahura WAR dengan baik sehingga berdampak pada peningkatan pendapatan, peningkatan kemampuan, serta perkembangan usaha tani masyarakat KPPH Tahura WAR. Meskipun demikian masih terdapat kendala dalam pengelolaan Tahura WAR sebagai objek wisata dimana terdapat 2 objek wisata saat ini kurang terawat. Tingkat keberhasilan pengeloaan Tahura WAR di Provinsi lampung tersaji pada Tabel 4.

Tabel 4. Tingkat Keberhasilan Pengelolaan Tahura WAR di Provinsi Lampung berdasarkan Indikator

\begin{tabular}{llll}
\hline No. & Keberhasilan & Rerata Skor & Klasifikasi \\
\hline 1. & Output & 13.97 & Berhasil \\
2. & Outcome & 16.93 & Berhasil \\
3. & Benefit & 8.57 & Berhasil \\
\hline
\end{tabular}

Sumber: data yang diolah, 2019

Tabel 4 menunjukkan bahwa output atau keluaran (terlaksanakannya fungsi-fungsi Tahura WAR sebagai objek wisata, tempat penelitian, tempat konservasi beragam flora dan fauna, tempat pencegahan bencana alam, dan sebagai tempat untuk pemenuhan kebutuhan sehari-hari melalui pemanfaatan hasil hutan) masuk dalam kategori berhasil. Hal tersebut disebabkan karena pengelolaan dan fungsi Tahura WAR telah terlaksanakan dengan baik.

Tahura WAR sebagai objek wisata berupa Rumah Pohon, Taman Kupu-Kupu Gita Persada, Taman Wisata Hutan Kera, Pasar Tahura, Youthcamp Tahura WAR. Namun saat ini, terdapat dua objek wisata yang kurang terawat yaitu rumah pohon dan taman kupu-kupu yang berlokasi di Kelurahan Sumber Agung sehingga tidak dapat menarik pengunjung. Faktor lingkungan juga mempengaruhi eksistensi kedua objek wisata tersebut karena saat musim kemarau, lokasi wisata tersebut menjadi gersang sehingga kurang menarik untuk dikunjungi. Tahura WAR sebagai tempat penelitian yaitu berupa penelitian yang dilakukan oleh pihak luar untuk meneliti ekosistem Tahura WAR seperti penelitian tentang biota tanah yang terdapat didalam tanah Tahura WAR, penelitian tentang tanaman tajuk tinggi, dan lain-lain. Tahura WAR sebagai tempat konservasi beraneka ragam flora dan fauna yaitu adanya tempat penangkaran rusa Tahura WAR, selain itu Tahura WAR juga memiliki blok khusus sebagai blok perlindungan tumbuhan, satwa maupun ekosistem untuk menjaga kelestarian Tahura WAR. Tahura sebagai tempat pencegahan bencana alam yaitu ekosistem Tahura WAR berperan dalam mencegah bencana alam seperti banjir ataupun tanah longsor. Tahura WAR sebagai tempat untuk pemenuhan kebutuhan sehari-hari melalui pemanfaatan hasil hutan yaitu masyarakat KPPH Tahura WAR dapat memanfaatkan hasil dari tanaman yang mereka kelola untuk memenuhi kebutuhannya. Berdasarkan data yang didapatkan, semua fungsi Tahura WAR telah berhasil dilaksanakan dan dikelola dengan baik bersama masyarakat.

Outcome atau hasil (peningkatan pendapatan masyarakat anggota KPPH Tahura WAR, peningkatan kemampuan KPPH) masuk dalam kategori berhasil. Hal ini disebabkan oleh UPTD Tahura WAR yang berupaya agar masyarakat dapat memperoleh akses legal dalam memanfaatkan lahan Tahura WAR. Masyarakat yang telah menggunakan lahan Tahura WAR dapat memanfaatkan hasil hutan dari tanaman yang mereka kelola untuk kebutuhan sehari-hari maupun untuk diolah agar mendapatkan nilai ekonomi yang lebih tinggi. Beberapa KPPH memiliki usaha kopi bubuk dari hasil kopi yang dipanennya, salah satunya adalah Kopi Gunung Betung. Selain itu, UPTD Tahura WAR juga sering melakukan penyuluhan kepada KPPH sehingga terjadi peningkatan kemampuan KPPH dalam melakukan budidaya tanaman yang mereka kelola serta peningkatan kemampuan dalam hal pengelolaan hasil panen.

Benefit atau manfaat (perkembangan usaha pertanian) dari pengelolaan Tahura WAR masuk dalam kategori berhasil. Perkembangan usaha 
pertanian berupa perubahan sistem tanam yang menjadi sistem agroforestri dimana tanaman kayu yang telah ditanam kemudian dikombinasikan bersama dengan tanaman non kayu. Penerapan sistem agroforestri tentu saja berdampak pada peningkatan keuntungan baik secara ekonomi maupun lingkungan. Hasil temuan penelitian ini mendukung pendapat (Choiria, Hanafi, \& Rozikin, 2015), bahwa capaian hasil pemberdayaan masyarakat adalah terjadinya peningkatan pendapatan masyarakat yang telah berhasil mengelola hasil hutan menjadi produk yang memiliki nilai ekonomi tinggi.

\section{Hubungan Keberdayaan Masyarakat dan Keberhasilan Pengelolaan Tahura WAR}

Berdasarkan hasil analisis, diperoleh nilai koefisien korelasi 0,6613 dan nilai signifikansi sebesar 0,000. Hal tersebut memiliki makna bahwa terdapat hubungan yang kuat dan nyata antara keberdayaan masyarakat dengan keberhasilan pengelolaan Tahura WAR di Provinsi Lampung, dimana semakin tinggi keberdayaan masyarakat sekitar hutan maka semakin tinggi juga tingkat keberhasilan pengelolaan Tahura WAR di Provinsi Lampung. Hasil temuan ini mendukung penelitian (Monalisa, 2010), yaitu semakin baik pengetahuan, sikap, dan keterampilan pelaku kewirausahaan maka semakin baik tingkat keberhasilan usaha yang akan dicapai.

\section{KESIMPULAN DAN SARAN}

Tingkat keberdayaan masyarakat sekitar Tahura WAR secara keseluruhan masuk dalam klasifikasi sedang. Hal tersebut berdasarkan tingkat pendidikan yang rendah sehingga kurangnya keterampilan masyarakat KPPH Tahura WAR dalam mengelola Tahura WAR. Keberhasilan pengelolaan Tahura WAR termasuk dalam kategori berhasil secara keseluruhan. Hal tersebut didasarkan pada pengelolaan Tahura WAR dalam menjalankan fungsinya telah berlangsung dengan baik sehingga berdampak pada peningkatan pendapatan serta perkembangan usaha pertanian masyarakat KPPH Tahura WAR. Keberdayaan masyarakat sekitar
Tahura WAR memiliki hubungan nyata yang kuat dengan keberhasilan pengelolaan Tahura WAR di Provinsi Lampung.

Kepada Dinas Kehutanan dan UPTD Tahura WAR untuk dapat meningkatkan keberdayaan masyarakat melalui program pemberdayaan sehingga Tahura WAR dapat dimanfaatkan dengan lebih optimal. Bagi penelitian selanjutnya diharapkan dapat memperluas area pengambilan sampel sehingga dapat diperoleh data yang menyeluruh terkait pengelolaan Tahura WAR.

\section{UCAPAN TERIMA KASIH}

Terimakasih kepada masyarakat sekitar Tahura WAR di Kelurahan Sumber Agung, Kota Bandar Lampung atas kesediaan waktunya sehingga penelitian ini dapat terlaksana.

\section{Daftar Pustaka}

Alviya, I. (2006). Penetapan Hutan Lindung Gunung Ceremai menjadi Taman Nasional dan Da mpaknya bagi Ma syarakat SekitarKa wasan. Jurnal Analisi s Kebijakan Kehutanan, 3 (2), 87-94.

Anggra ini, R., Rangga, K. K., \& Ha sanuddin, T. (2019). Partisipasi Petani dan Keberhasilan Program Pengembangan Usaha Pangan Masyarakat (PUPM) di Kecamatan Palas Kabupaten Lampung Selatan.

Choiria, I., Hanafi, I., \& Rozikin, M. (2015). Pemberdayaan Masyarakat Desa Hutan melalui Lembaga Masyarakat Desa Hutan (LMDH) sebagai Upay a Meningkatkan Pendapatan Masyarakat. Jurnal Administrasi Publik, 3(12), 2112-2117.

Departemen Kehutanan. (2014). Hutan Kemasyarakatan $(H K m)$. http:bp2sdmk.dephut.go.id. Diakses p ada 09 Juli 2019.

Haryanto, T.D. (2011). Pengelolaan Sumberdaya Hutan Bersama Masyarakat dalam Sistem Agroforestry. Jurnal Wacana Hukum, 10 (1), 17-30.

Hasanuddin, T., \& Muhammad, D. (2012). Tingkat Keberhasilan Program Pengembangan Usaha Agribisnis Perdesaan (PUAP) da lam Meningkatkan Penda patan dan Keberdayaan Masyarakat Petani di Pedesaan. Jumal Activita, 4 (2), 151-167.

Monalisa. (2010). Pengaruh Perilaku Kewirausahaan terhadap Keberhasilan Usaha pada CV. Karaos Cattering diBandung. Jurnal Unikom, 1 (2), 59-72.

Nurlia, A., Martin, E., \& Winarno, B. (2015). Kajian Pengelola an Kolaboratif Ka wasan Hutan di Taman Hutan Raya Wan Abdul Rahman, Provinsi Lampung. 
Prosiding Seminar Hasil Penelitian Aspek Sosial Ekonomi dan Kebijakan, Palembang, Agustus 2015.

Setyaningsih, E., Gayatri, S., \& Eddy, B. T. (2017). Faktor-faktor yang Mempengaruhi Tingkat Pengetahuan Ibu Rumah Tangga tentang Konsep Daging Sa pi yang Asuh di Desa Baturetno Kabupaten Wonogiri. Jurnal Agrisocionomics, 1 (2), 122-134.

Sugiatono, E., \& Dharmayanthi, W. (2016). Model Pemberdayaan MasyarakatdiSekitar Kawasan Hutan Kabupaten Jember. Prosiding Seminar Nasional Penelitian dan Pengabdian Masyarakat, Jember, 2016.

Suwarno, Sa rtohadi, J., Sunarto, \& Sudhart a, J. (2014). Kajian Pengaruh Tingkat Pendidikan terhadap Perilaku Ma syarakat dalam Pengelolaan Lahan Rawan Longsor di Keca matan Pekuncen Kabupaten Banyumas. Jurnal Geoduksi, 3 (1), 15-22.

Tim SHK Lestari. (2008). Inventarisasi Potensi Tumbuhan dan Satwa Liar sebagai Pendukung Ekowisata di Lokasi Kelola SHK LestariTahura Wan Abdul Rachman. Laporan Hasil Penelitian, Bandar Lampung.

UPTD Tahura WAR. (2006). Master Plan Tahura Wan Abdul Rachman Reg. 19 Gunung Betung. . Bandar Lampung: UPTD Tahura WAR.

UPTD Tahura WAR. (2017). BlokPengelolaan Taman Hutan Raya WanAbdulRachman. Bandar Lampung: UPTD Tahura WAR.

Winarwan, D. (2011). Kebijakan Pengelolaan Hutan, Kemisikinan Strukturaldan Perla wanan Ma syarakat. Jurnal Kawistar, 1 (3), 213-224. 